\title{
Postmenopausal women and physical activity: A challenge for healthy aging
}

\author{
Fiona Barnett
}

The postmenopausal period for a woman today is very different to that of 100 years ago. Advancements in healthcare have meant that life expectancy in the Western world is 82.5years compared to 55.5 years in the early 20 th century [1]. Therefore, a woman of today should expect to live a further 30 years beyond menopause. This increased longevity may pose a challenge to a postmenopausal woman's quality of life if she is not in good health. In Australia, the leading causes of death in older persons are heart disease, stroke and cancer. In addition, obesity rates are increasing with three in five adults either overweight or obese [2]. These comorbidities are thought of as lifestyle diseases, brought on by a combination of a sedentariness and poor dietary choices.

Physical activity, however, is believed to be one of the most important non-pharmacological preventative treatments for reducing the health risks associated with lifestyle diseases. Regular moderate intensity physical activity has been found to reduce the risk of cardiovascular disease by up to $58 \%$, type 2 diabetes by $46 \%$ and breast cancer by up to $67 \%$ [3]. In addition to the physiological benefits, regular moderate intensity physical activity has many known psychosocial benefits such as improving quality of life, enhancing self-efficacy and mood and offers opportunities for socialization. So, despite the known benefits, why are so few postmenopausal women participating in exercise?

The answer can be found in the determinants of physical activity. A postmenopausal woman's decision to

Fiona Barnett

Affiliations: Sport \& Exercise Science Discipline, James Cook University, Australia.

Corresponding Author: Fiona Barnett, Sport \& Exercise

Science Discipline, James Cook University, Australia; Email: Fiona.Barnett@jcu.edu.au

Received: 22 June 2015

Published: 01 August 2015 exercise will be influenced by many determinants at both the individual level as well as the environmental level. Individual determinants include a perceived lack of time, a lack of motivation and safety concerns. Environmental determinants include social support, access to facilities and climate [4]. These determinants can act as barriers to undertaking physical activity. Postmenopausal women who are working are particularly prone to the perception of lack of time, as they may be caring for children as well as elderly parents. For women to engage in physical activity, facilities must be affordable, aesthetically pleasing and be undertaken with others such as a partner or friends [5]. For example, the hot, humid climate in northern Australia can be a deterrent to exercising outdoors, whereas in the southern regions of Australia it is the winter months which lead to less physical activity participation. Strategies are, therefore, needed in order to overcome these barriers before physical activity can be sustainable.

I have found that given the opportunity, previously sedentary postmenopausal women can find exercise to be an enjoyable experience providing they are given the appropriate support and encouragement. It is important that women choose an activity that is meaningful to them and is easily mastered so as to improve their selfefficacy at completing the activity. Group-based activities have proven particularly successful for offering a nonthreatening environment for postmenopausal women. An exercise intervention program, we have in our exercise physiology clinic involves circuit-style exercise incorporating resistance and aerobic-type activities. Physiological benefits we have seen include increases in strength and cardiovascular fitness, maintenance of bone density and decreases in waist girth and cholesterol while the reported psychosocial positives include the fun group atmosphere, the lack of feeling self-conscious and the friendly competitiveness.

Physical activity can come in many different forms. Exercise is structured physical activity whereby the activity conforms to the specific principles of frequency, intensity and duration. For example, 150 minutes per week of moderate-intensity activities such as walking, swimming and cycling. Incidental physical activity 


\section{EDORiUM Journals}

Edorium J Aging Res 2015;1:14-16.

Barnett

includes tasks such as walking to the shops, to and from work and taking the stairs instead of taking the lift. Recreational activities are pursuits that a person enjoys doing but requires movement such as taking the dog for a walk and gardening. Unfortunately, our lives have become particularly sedentary as a result of modern technology. An Australian Institute of Health and Welfare survey [6] found that over $60 \%$ of females sat for between 3-6 hours during their leisure time, while a further 10\% sat for 7-11 hours. It is up to health professionals to encourage participation in physical activity in all of its forms during work hours and leisure hours. It is also important for health professionals to develop strategies which will help our patients and clients in overcoming the barriers to physical activity participation, allowing the years spent in the postmenopausal period to be both healthy and enjoyable.

Keywords: Postmenopausal women, Healthy aging, Life expectancy, Physical activity, Exercise

\section{How to cite this article}

Barnett F. Postmenopausal women and physical activity: A challenge for healthy aging. Edorium $\mathrm{J}$ Aging Res 2015;1:14-16.

Article ID: 100003Ao3FB2015

$* * * * * * * * *$

doi:10.5348/Ao3-2015-3-ED-3

\section{Author Contributions}

Fiona Barnett - Substantial contributions to conception and design, Acquisition of data, Analysis and interpretation of data, Drafting the article, Revising it critically for important intellectual content, Final approval of the version to be published

\section{Guarantor}

The corresponding author is the guarantor of submission.

\section{Conflict of Interest}

Authors declare no conflict of interest.

\section{Copyright}

(C) 2015 Fiona Barnett. This article is distributed under the terms of Creative Commons Attribution License which permits unrestricted use, distribution and reproduction in any medium provided the original author(s) and original publisher are properly credited. Please see the copyright policy on the journal website for more information.

\section{REFERENCES}

1. World Health Organization (WHO). World Health Statistics 2010. [Availabe at: http://www.who.int/ whosis/whostat/2010/en/]

2. Australian Institute of Health \& Welfare (AIHW). Australia's Health 2010. Australia's health series no. 12. Cat. No. AUS 122. Canberra 2010.

3. Brown WJ, Burton NW, Heesch KC. (2007) Physical activity and health in mid age and older women. Canberra: The Office for Women, Department of Families, Community Services, and Indigenous Affairs.

4. World Health Organization (WHO). Promoting physical activity and active living in urban environments 2006. [Availabe at: http://www.euro. who.int/__data/assets/pdf_file/ooo9/98424/ E89498.pdf]

5. Ball K, Bauman A, Leslie E, Owen N.. Perceived environmental aesthetics and convenience and company are associated with walking for exercise among Australian adults. Prev Med 2001 Nov;33(5):434-40.

6. Australian Institute of Health and Welfare 2012. Australia's health 2012. Australia's health series no.13. Cat. no. AUS 156. Canberra: AIHW. 


\section{EDORIUM Journals}

Edorium J Aging Res 2015;1:14-16.

Access full text article on other devices

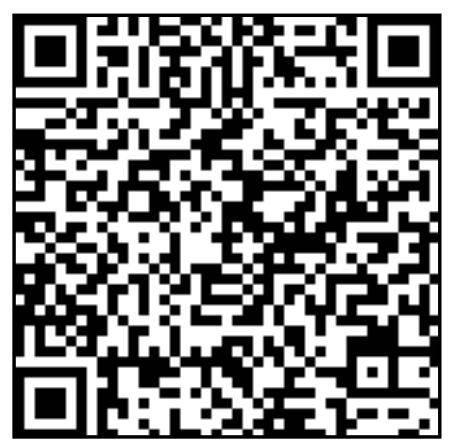

Access PDF of article on other devices

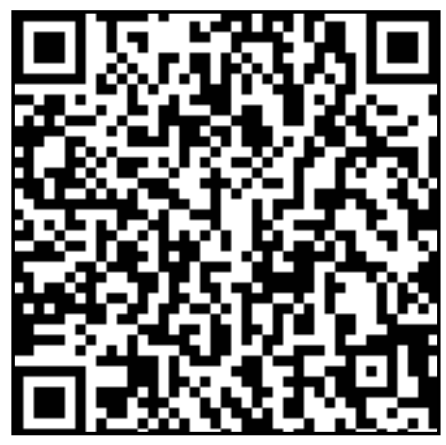

